\title{
Los Estudios Brasileños en las Universidades de los Estados Unidos
}

F el "Instituto de Estudios Latinoamericanos que tuvo 1 lugar en la Universidad de Michigan" en el verano de 1938, bajo los auspicios del Comité de Estudios Latinoamericanos que forma parte del American Council of Learned Societies, se celebró una conferencia especial sobre estudios brasileños. En este Instituto se dictaron cursos sobre la lengua portuguesa, $\mathrm{y}$ el historiador y sociólogo brasileño Gilberto Freyre estuvo encargado de un seminario sobre la historia social del Brasil. La conferencia se convocó para indagar en particular qué cursos se ofrecían actualmente en este ramo y qué personas se ocupaban de investigaciones luso-brasileñas. El Comité también estudió la necesidad de publicar un "Manual de Estudios Brasileños", provisto de una bibliografía selecta del material en las varias disciplinas que se había publicado antes de 1985, fecha de la inauguración del Handbook of Latin American Studies. A la vez que se propuso el nuevo volumen, se pensó que sería oportuno preparar un informe, lo más completo posible, que diese a conocer la presente situación de los estudios brasileños en los Estados. Unidos para averiguar si actualmente existe suficiente interés en la materia para justificar la publicación del propuesto "Manual de Estudios Brasileños". El informe preparado, amplificado y puesto al día, es la substancia de este artículo.

Los resultados de esta investigación muestran un serio 
sistema de estudios ya organizados, los cuales indican el desarrollo de un programa mucho más extenso para el futuro. En todos los colleges y las universidades se nota una convicción creciente de que el Brasil merece un puesto especial en sus cursos. Se están considerando los siguientes cursos: la lengua portuguesa, cuya necesidad se ha notado desde hace diez años; el estudio de la colonización portuguesa y la de Iberoamérica; investigación del problema racial en el Brasil como uno de los elementos más importantes de la sociología americana; la geografía y economía de las principales repúblicas iberoamericanas. Los estudios brasileños, recientemente emprendidos, prometen un desarrollo considerable.

\section{Cursos de Historia Brasileña}

El número de cursos que se ofrecen sobre la historia en general del Brasil exceden en mucho a los otros cursos. En el presente año académico se ofrecen unos 70 cursos sobre historia iberoamericana en 40 calleges y universidades americanas. De estos 70, uno solo se dedicó exclusivamente al Brasil. El Profesor Frederick Ganzert, de la Universidad de Utah, inauguró, hace un año, un curso titulado "El Brasil Colonial, Imperial y Republicano". El Profesor Ganzert declara que se encuentra ante dos problemas principales: primero, que los estudiantes no saben leer portugués - lo cual se comprende fácilmente-, y segundo, la falta de buenos libros de texto, escritos en inglés, sobre el Brasil. El espera que esta dificultad se podrá enmendar al publicarse la traducción que está preparando el Profesor P. A. Martin de la Formação historica do Brasil por J. B. Calógeras. Pero estos dos problemas suscitan la cuestión esencial que afecta el continuo desarrollo de cursos especializados brasileños: la incapacidad de los estudiantes para leer la gran cantidad de material esencial que existe, no traducido al inglés. Así que la enseñanza de la lengua portuguesa se hace obligatoria en cualquiera institución que ofrezca un curso como el que mencionamos arriba.

Se ofrecen dos cursos sobre "Historia del Portugal y sus Colonias", el del Profesor Zing en la Universidad de Denver, y el del Profesor Coutinho en el Departamento de Servicios 
Extranjeros de la Universidad de Georgetown. Este curso del Profesor Coutinho, por ofrecerse en un Departamento de Graduados, de carácter especial, ha atraído a muchos estudiantes extraordinariamente bien preparados para solucionar el problema lingüístico. Pero se debe tener presente que el Dr. Coutinho también enseña la lengua portuguesa en la Universidad de Georgetown, y desde hace muchos años ha sido uno de los principales promotores de la extensión de la enseñanza del lenguaje portugués en este país.

En el campo de cursos de estudios generales y semi-especializados, el Brasil ocupa un puesto de menos importancia en las siguientes materias: "Historia de las Américas" e "Historia de la América Latina" o de Sudamérica en general.

\section{CuRsos DE LA Lengua Y Literatura Portuguesa}

El interés que, con respecto al portugués, existe en las universidades de este país ha sido principalmęnte filológico. En Harvard, el Profesor J. D. M. Ford ha enseñado, por más de cuarenta años, un curso para estudiantes graduados relativo a la lengua portuguesa y su literatura (el portugués antiguo, poesía lírica; Gil Vicente; Sá de Miranda). En la Universidad de Pennsylvania el Profesor Edwin B. Williams ofrece una "Introducción al estudio del portugués antiguo" y un seminario para graduados sobre el portugués antiguo. También hay un curso sobre el portugués antiguo en la Universidad de Kansas y otro en la Universidad de Yale (Raymond T. Hill). No pueden ser consideradas en estos cursos la lengua y literatura del Brasil, aunque en Harvard asigna de vez en cuando el estudio de una novela clásica de Taunay.

En los siguientes centros docentes se ofrecen actualmente cursos elementales y prácticos de portugués: Universidad de Boston (James Geddes) ; California (Leo Kirschenbaum); College of the City of New York (portugués comercial) ; Dartmouth (Folger); Florida (Othon Moacyr García); Georgetown, Departamento de Servicios Extranjeros (J. de S. Coutinho); Kansas (no se ofrece todos los años); Universidad de Miami (Alexandre José de Seabra) ; Texas; George Washington (Raul d'Eça); Wisconsin (H. D. Berkowitz). Hay 
clases avanzadas en las universidades de Boston, Columbia (Seminario Hispánico de Federico de Onís), Georgetown (Coutinho) y Wisconsin.

En Dartmouth el Profesor Arce tiene una clase especial sobre los pueblos y la civilización iberoamericanos, que trata ligeramente de la civilización y literatura brasileñas. Sin embargo, no hay un curso verdadero completo sobre la literatura brasileña ahora que el Profesor Berrien se ha trasladado a Northwestern y dejó de dar los dos cursos que tenía en California. No obstante, el Profesor Torres-Rioseco proyecta introducirlos de nuevo, y arreglos semejantes, favoreciendo cursos que traten enteramente de literatura brasileña, se están haciendo en las universidades de Miami, Texas y Wisconsin.

\section{Cursos DE ANTropología}

Los Profesores Lesser, de Columbia; Coon, de Harvard y Bennett," de Wisconsin, en sus clases sobre las "Razas y culturas de la América Central y del Sur", dedican parte del tiempo a la discusión de temas brasileños. Pero aún no hay cursos en esta materia que traten exclusivamente del Brasil.

\section{CURSOS DE ECONOMIA}

Se dicta el curso "Problemas y recursos comerciales de la América Latina" en seis universidades (Michigan, North Dakota, Pennsylvania, Texas, George Washington y Wisconsin), pero el verdadero centro de actividad, actualmente, es el Wharton School of Finance de la Universidad de Pennsylvania. En este último ofrecen tres cursos relacionados con el Brasil, uno especialmente para licenciados (Relaciones comerciales de la América Latina, del Profesor Inman). Pero ni en este centro se dicta curso alguno dedicado exclusivamente al Brasil.

\section{CURSOS DE EdUCACIÓN}

La Universidad de Pennsylvania hizo un experimento singular en materia de educación el verano pasado, por prime- 
ra vez. El Profesor' Arthur Jones y la señora L. J: Sheridan llevaron un grupo de sus estudiantes a Río de Janeiro. Partieron el 16 de junio y regresaron el 9 de agosto. Siguieron dos cursos regulares: "La educación secundaria en el Brasil" e "Historia de la educación latinoamericana". El Dr. Gustavo Lessa atendió muy eficazmente a los estudiantes y se encargó del segundo curso. Además, varios estudiantes brasileños siguieron ciertas clases y explicaciones de los métodos de enseñanza norteamericanos. Este es el único estudio que se hace en los Estados Unidos, o desde este país, sobre la educación en el Brasil.

\section{Bellas ARTES y ARQUEOLOGfa}

El curso mâs adecuado en esta materia es el del Profesor George Kubler del Departamento de Bellas Artes en Yale: "El arte y la arqueología de la América Latina", aunque, por ahora, se relaciona con el Brasil sólo en lo que toca a la cultura primitiva de la Isla de Marajó y a las reliquias amazónicas. El Profesor Kubler explica que por ser su curso principalmente para los estudiantes de arquitectura práctica, su estudio tiene prioridad al de la escultura, la pintura, y el arte popular (folk art). El material estudiado se refiere a los edificios de México y del Perú, y principalmente a los precolombinos. No obstante, el Profesor Kubler piensa organizar" el próximo año un "Seminario de arte latinoamericano", en el cual el Brasil desempeñará el papel mayor.

Cursos de Geografia

En los cursos de "Geografía de la América Latina" y de "Sudamérica" que se siguen en siete universidades (California, Colorado, Chicago, Harvard, Michigan, Pennsylvania $\mathrm{y}$ Wisconsin), todos para estudiantes no graduados aún, se incluye al Brasil, $y$ en algunos se le da un puesto preferente. Pero aún no se ha organizado una clase regular para el estudio especializado de la geografía brasileña.

CuRsos DE Sociología

En relación con la sociología brasileña, la Universidad de Fisk da el único curso que existe en los Estados Únidos. 
El Dr. Rüdiger Bilden ofrece allí un curso de "Problemas raciales del Brasil". "Este grupo estudia -informa el Profesor-temas como el de la actitud racial del Portugal; la colonización portuguesa; la sociedad de los esclavos en el Brasil; la evolución de la nación brasileña a través de la mezcla racial y cultural; y compara la esclavitud de los negros y las relaciones raciales en la América portuguesa, las Antillas y Norteamérica. Mientras se le da la importancia merecida a la raza negra y al papel que desempeña en la sociedad brasileña, también se hace la comparación entre el Brasil y la América española con respecto a la política indianista, a las funciones económicas del indio, su contribución cultural y su posición social". Durante los últimos dos años unos 30 estudiantes han seguido este curso, siendo 24 de ellos graduados.

La posición de Fisk fué fortalecida aún más el año pasado por la asistencia del Dr. Donald Pierson en este mismo departamento, por ser él una autoridad en los problemas de los negros brasileños, habiendo hecho ya investigaciones extensas para la Universidad de Chicago y el Social Science Research Council (Instituto de Investigaciones en las Ciencias Sociales) en Salvador (Baía) desde 1935 hasta 1937.

\section{INSTITUTOS Y FUNDACIONES}

El "Instituto de Estudios Jesuitas", de la Universidad de Loyola. El Padre Juan Delanglez está estableciendo archivos de documentos en facsímiles y reproducciones fotostáticas, relacionados con los jesuítas del Portugal y del Brasil. Recientemente, el Padre Joaquim Leite encomió este proyecto en su Historia da Companhia de Jesus no Brasil, obra monumental publicada en Lisboa, 1938.

\section{La Fundación Hispánica de la Biblioteca DEL CONGRESO}

La "Fundación Hispánica", aunque no está asociada con ningún centro de enseñanza, merece ser incluída en este informe. Hace unos meses que se estableció y tiene por objeto la reunión de materiales concernientes al mundo hispáni- 
co. La Fundación se propone dedicar la parte merecida de su programa al Brasil, igual que a la América hispana. En sus colecciones de publicaciones, así como en el proyectado Archivo Fotográfico, dicha Fundación intenta reunir una colección sin igual de materias relacionadas con el Brasil. Se espera que le dará gran impulso y beneficio al fomento de los estudios brasileños en los Estados Unidos.

\section{CONCLUSIONES}

De este informe se puede deducir que ciertos centros de enseñanza superior de los Estados Unidos, por medio de sus cuerpos de profesores 0 del equipo que poseen, tienen ya un comienzo bastante respetable en el campo de los estudios brasileños. Las siguientes universidades pertenecen a esta categoría: Michigan (geografía y economía); Pennsylvania (educación, economía, historia); Yale (bellas artes); Fisk (sociología); California (literatura, geografía, historia); Stanford (historia); Harvard (historia, geografia, antropología) ; Utah (historia) ; y Wisconsin (economía, antropología, arqueología).

Es de interés observar que la mayoría de estos centros docentes son las grandes universidades. Podemos entonces inferir que nuestros estudios brasileños se localizan, por ahora, en unas cuantas grandes instituciones, ricas y sumamente desarrolladas, y que los centenares de centros educativos menores y de escuelas normales por todo el país no ofrecen nada en esta dirección. Desde luego, no pueden desarrollar todavía cursos de bellas artes, literatura, geografía, sociología o economía. Pero la mayoría de estos centros tienen departamentos de historia bastante bien desarrollados con respecto a otros campos. No podemos pretender que los estudios brasileños hayan alcanzado un puesto adecuado hasta que estos institutos menores, pero esenciales, comiencen a dar clases de historia iberoamericana que traten del Brasil. Además de lo político y económico, estas clases, con el tiempo, deben llegar a representar otros aspectos de la cultura brasileña, hasta que se enseñe la historia social, la música, el teatro, etc. Este desarrollo fomentaría formidablemente el 
interés en los estudios brasileños y favorecería la organización de estudios más especializados.

Por último, es evidente que el estudio de la lengua portuguesa tiene que extenderse mucho durante los próximos años, por ser la base fundamental de que depende, en último término, el verdadero éxito de los cursos especializados dedicados completamente a los estudios brasileños.

$$
\begin{aligned}
& \text { Robert C. SMrTH, } \\
& \text { The Hispanic Foundation, } \\
& \text { Library of Congress. }
\end{aligned}
$$

